УДК $16+165$

\title{
Continualism by Aleksandr Svitin and Western Scientific-Philosophical Tradition: on Grounds of Informational Chemistry
}

\author{
Valery V. Mineyev* \\ Krasnoyarsk State Pedagogical University \\ named after V.P. Astafiev \\ 89 Ada Lebedeva Str., Krasnoyarsk, 660060, Russia
}

Received 11.09.2014, received in revised form 06.10.2014, accepted 20.12.2014

This article is devoted to the analysis of the monograph by Professor A.P. Svitin "Nondestructive Knowledge: The Sum of Ontologies". Merits and lacks of the original scientific and philosophical concept offered by A.P. Svitin are reconsidered. In particular, an attempt to estimate possibility of continualism in further evolution of a chemical science is undertaken. It is shown that informational chemistry is rather dialectic denial of informational physics, than its direct continuation.

Keywords: history of science history, philosophy of science, informational chemistry, continualism, the problem of being.

Research area: philosophy

In postnonclassical science the concept of global evolutionism becomes an interdisciplinary methodological basis of generalization of knowledge and, consequently, a theoretical framework of the updated picture of the world (Jantsch, 9-27). First of all, it emerged as a synthesis of system and evolutionary approaches. Secondly, its appearance was due to the convergence of natural and social sciences and humanities. Thirdly, it appeared because of the need to assess the role of the human in the biosphere more deeply and in connection with the ecologization of science. Fourthly, and this, in our opinion, is the main cornerstone of the issue, it appeared as a product of interaction of specific scientific theories, philosophical doctrines at a time when the materialistic paradigm itself is almost exhausted, and the traditional religious view of the world fails to meet the needs of scientists. We are talking about general scientific concepts, in which a variety of generalized knowledge about the mechanisms of evolution and the world is seen as a single self-organizing integrity. The global evolutionism replaced the "local one", and united such dissimilar authors as Teilhard de Chardin, E. Jantsch, I. Prigozhin, A.P. Nazaretyan (Global'nyi evoliutsionizm) The path to the new synthesis was a long one: general theory of systems, catastrophe theory, non-equilibrium thermodynamics, cybernetics,

(C) Siberian Federal University. All rights reserved

* Corresponding author E-mail address: vvmineyev@mail.ru 
synergetics. It has often been noted that the prospects of further development of the global evolutionism are linked to an explanation of the deep unity of the statistical thermodynamic entropy and information treatments (Mineev, 2009, 245-269). The combination of these concepts would allow to picture the universe as a self-governing system, including humanity as its essential element. In this universe not only electromagnetic waves or molecular genetic codes can work as means of communication, but also symbols of culture and laws of nature can comply with the system programs, and at some point of evolution can coincide with moral values.

Information approach, which has become part of a new general scientific synthesis is used in various fields of natural science, but it is of a local nature, is not up to the standard of a global evolutionary paradigm yet. In this context, the publication of the monograph "Non-Destructive Knowledge: The Sum of Ontologies" by Doctor of Philosophy, Professor A.P. Svitin seems to be a very important milestone in the development of national scientific and philosophical thought in general, and in the development of information chemistry in particular. The purpose of this article is to identify and, if possible, to clarify some of the basic preconditions of the problem areas (and therefore in terms of further growth) of the concept of "non-destructive knowledge", which have not been legitimized within the standard text of the book.

From the standpoint of the holistic approach, which is actively gaining recognition in recent decades, the author, who is a professional chemist and, at the same time, a professional philosopher, opposes the assumption that you can explore the world "without regard to its indivisible integrity - continuity" (Svitin, 2011, 8). The author is against technocratic attitude towards nature and, consequently, against the instrumentalist understanding of science. His theoretical search was reflected by new not very common expressions: "science adequatising", "greening of knowledge", "antigenic technoworld", "genetic biosphere", "nature-made civilization" and similar ones (Svitin, 2011, 1213). The terms are quite in the spirit of the time: despite the scientistic sound the content is loaded with a more anti- scientistic, humanistic essence. And it is symptomatic. Scientific thought is trying to return to its roots in life, to existence in its entirety, but the long-awaited return still remains a challenge. As it always happens in such cases, at first it is carried out under the sign of the revival of the true meaning of those ideas, which allegedly suffered distortion; it is carried out within the limits specified by an alien conceptual apparatus, in a foreign language, bearing the stamp of rejected physicalistic settings (Svitin, 2011, 28). Nevertheless, the uncomplicated, original pure source, that nourishes the continualistic approach, simultaneously supports the integrity and consistency of the author's arguments: “... If the main purpose of science is searching for truth, and not the use of nature, in that case human apparently has no way to be materialized other than Homo-Science" (Svitin, 2011, 16).

In our opinion, the drama of the history of Western civilization, the civilization which seems to have appeared primarily due to the thirst for knowledge (remember the ideas of Michel Foucault), this civilization through the words of its brightest thinkers constantly repeats that it has lost the ability to understand (remember Husserl, Heidegger, Lacoue-Labarthe) and the ability to learn in the best sense of the word, which refers to the knowledge of the ancient Greeks. After all, they have already decided to oppose "multiknowledge" to "knowledge of the essence", "knowledge of the whole", "knowing everything" and outlined the cognitive and vital practical ideal of the word "philosophy". Many people today prefer to talk about the information, instead 
of thinking about knowledge and understanding. The concepts of knowledge and information are believed to be identical. In this we see one of many metamorphoses of positivism. So, it means that the informational approach so popular today, to which scientists and philosophers place their hopes, needs at least a radical rethinking of its key concepts in its return from physicalistic interpreted information processes to the original anthropological-ontological intuition, knowledge-being. It is on the pages of "nondestructive knowledge", where this return begins: information chemistry, as it is interpreted by A.P. Svitin, is to be carefully distinguished in its ontological, epistemological and sociological aspects, and it is not a continuation, so to speak, of "information physics", but rather, its dialectical negation.

The author of "non-destructive knowledge", has managed to embrace the seemingly enormous amounts of concrete scientific data. From the standpoint of the information approach the book consistently rethinks the puzzles of noise immunity and self-adjustment of biological systems, quantum phenomena, the theory of ensembles, the phenomenon of orbital symmetry, correlation between the structure and properties of molecular systems (vibronic effects), the status of dissipative structures, the ratio of stoichiometric and non-stoichiometric compounds in the environment (Berthollet-Proust controversy and Dalton's atomic theory). In contrast to the conjuncture of "materials science" the ideal of chemical tectology is strongly advocated. An extremely important conclusion is made that "the principles of post-discreet chemistry correspond to the principles of information chemistry". "Information chemistry, displaying in its models non-stoichiometric forms of organization of matter, which are more typical for nature-made chemical reality, take into account the integrity of chemical facilities" (Svitin, 2011, 234). Finally, based on the concept voiced by H.-P. Duerr in particular, a definition of chemical continualism is given, the subject of which is not so much a form of motion of matter, but its features of creative potentiality of the continuity of existence which have not been revealed yet (Svitin, 2011, 265). At first glance, the treatment may seem a bit expansive, but scientific concepts should go that way. Thus, an outline of a single general scientific (not just philosophical) picture of the universe is brought to light. Broad interpretation of chemical concepts, bringing them to the level of general methodological principles, to the level of philosophical metaphors gives the book a special charm. Phenomena of the natural sciences which seem to be prosaic are endowed with magic Heraclitean philosophy. The remarkable analogy between the maximum permissible concentration and "hedonistic aspects of human mental activity" (the effect of alcohol and drugs, relations libidifying, too loud and too rhythmic music), which are based on "super-concentration of non-nature made activators". (Svitin, 2011, 149). On the basis of Foucault's teachings on disciplinary power the idea of "chemical power" of man over the objects of chemical reality is being developed (Svitin, 2011, 161). Finally, the author makes an attempt to do away with the threat of physical reductionism by radically rethinking the subject of chemistry and reliably protects it from external attacks: "Chemistry ... can be seen as a way (the science or art) to activate inhibited, "sleeping" potentiality of the substance (matter) that could be called the potentiality of information, given the modality, which is attached to the concept of information in the broadest sense" (Svitin, 2011, 252-253). The approach is highly productive, though, for example, it is difficult to agree with the author of the book about the "modalities": the author warns the reader in advance that he intends to interpret "information" in two "registers" (Svitin, 2011, 
17). It is logical, of course, to call orderliness, resolution, and shape "information parameters" (Svitin, 2011, 17), that is, obviously, everything that meets the criteria of Galilean primary qualities. But why, in that case (in favor of objectivist-materialist tradition?), to use exactly the same word for designating something that these "parameters" should be opposed to - "a lot of the characteristics of the content of the world" (Svitin, 2011, 17)? The well-known discussion of P. Virilio against adherents of the informational approach in its traditional form, the echoes of which are heard from the pages of major work by A.P. Svitin (Svitin, 2011, 195-201), to put it mildly, has not finished. Information processing, by definition, is not equal to understanding of the meaning. Computers and people and other natural systems are able to effectively process information without understanding it! Moreover, not all things are subject to objectification. Not for the actual existence or the subjective experience (or rather, qualia) or the objective meaning or perhaps on many more can not be shown with your finger, as a thing among the things around us. Neither the existence nor the mental states can be expressed without the loss of the contents (avoid the word "information"!) through the language of physics (this allegation is proved by the whole history of philosophical thought of Hume and Kant to Heidegger and Chalmers). As Heidegger believed, you can just let the being to be through us (Heidegger, 1993, 391-406). But how to transfer knowledge by the means of the updated non-physicalist theory of information? Here, of course, the point is not in how we call it (an old word or a new one), but about whether or not we have reached a new understanding of the eternal philosophical problem, which would allow us to reformulate it and to offer the best solution.

Meanwhile, we stake the property of "indivisible integrity", the unity of space being supplied, in which, following the exact words of the author, not just built-in, but "implanted" biological systems (Svitin, 2011, 25) and which, we may add, can be finally acquired only through all-understanding spirit (and not a digital device), the all-pervading world-soul, in an act of selfknowledge (rather than reading information). The perfect fullness of being is the goal and tireless, non-mechanical motor for evolutionary and cosmic processes. An inexhaustible source of new and timeless "seat" of the eternal. Plato warns against the fatal error of thinking characteristic of the ordinary: "We ... assert that this being must necessarily be somewhere in some place and occupy some space, but something which is not on the ground or on Heaven seems to not exist" (Plato, 1971, 493-494). By demonstrating a brilliant synthesis of diverse and seemingly disparate philosophical traditions, one of the creators of modern science, mathematician, theologian and alchemist Isaac Newton wrote: “... There is an incorporeal being ..., that in infinite space, as in its sensory organ, sees all things near, sees through them and understands them completely because of their proximity to it" (Newton, 1954. 280-281). The immediate manifestation of this understanding is often identified as the divine love and omnipotence, the existence of acts of physical objects and their movement in space, the mutual attraction. Various interpretations of the concept of incorporeal beings are possible. What is important is that without this concept neither Newton nor Leibniz, nor Descartes or Hobbes or (somewhat earlier) Bacon could justify the so-called "mechanistic" view of the world to give it harmony and perfection that it could not have. Here we come to the problem of the origin of the modern natural sciences, in particular, the chemical paradigm, that once opened to mankind an unprecedented prospect of knowledge and transformation of the world, but to this point in time, obviously, have already exhausted its 
potential. And in order to really advance to the leading positions in the field of philosophy of science, continualism needs to clearly and distinctly answer some very difficult questions. More precisely, to answer them in a new way, as these questions are from the category of the eternal.

Firstly, why still for many centuries chemists were not ready to accept the hypothesis of the atomic structure of the matter? They praised Plato and Aristotle, but have not heard anything about the ideas of Democritus? Hardly. The teachings of Epicurus was popular. Mostly, of course, in the field of moral philosophy, but "physics" also knew about it. And in the end, why distant descendants of Jabir and Al-Razi changed their preferences? It is appropriate to recall the old post-scholastic debate about intussusception and juxtaposition. Suppose that a compound substance formed of atoms of two species. There is a dilemma. Or by simply reducing the amount of substance should have a new substance (identity of one of the varieties of the component atoms), or by entering a part of the whole, part cease to be what they were separately. From the perspective of modern chemistry, it is the way it is. But to accept it does not mean to understand it. Yes, a part bears the stamp of belonging to the integrity permeated and transformed the essence of a higher order, but a holistic (dialectical) approach is fundamentally contrary to the idea of existence of the eternal, indivisible, indestructible, immutable elements atoms. At the very least, contrary to the physical and mechanical interpretation of this idea. There could not be another interpretation at the dawn of the appearance of chemical atomism. It is no coincidence that carriers of chemical properties (mercury, copper, salt) were regarded (correctly) as ideal essences with spiritual qualities rather than similar to elastic ball of the matter. However, the atomistic ideas triumphed. What contributed to this? And what exactly was sacrificed for the nascent instrumental science and ideology of nature?

Secondly, why chemists for so long did not have a thermometer? Technical prerequisites for the emergence of such a useful device had been evident even before the beginning of our era, but the invention was not to be. Apparently, European chemists did not favor scales or clock (even water or sand clock, but after the discovery of the Antikythera mechanism, we could have expected more). Thisisdespite thetremendous achievements of such giants as Al-Biruni and Al-Khazin, who determined the specific weight of the materials (density) and actually outstripped their time at half a millennium. Again, the usual reference to the fatal influence of Aristotle, inherited from antiquity to disbelief in the possibility of the application of mathematics to the study of nature, does not seem convincing. Since alchemy developed in close connection with astrology, it included a set of highly mathematicised astronomical knowledge. We may take metals and planets symbolism, the principle of unity of the microcosm and the macrocosm, Neo-Pythagorean theory. But the example of the Observatory (the fact that the revolution in astronomy is not associated with the feat of Al-Tusi or Ulugbek but is associated with the name of a pygmy is a sad misunderstanding) did not inspired the lab. Obviously, chemical constituents within a single physical, astronomical and chemical-technical complex of knowledge resisted mathematization and instrumentalization. It constituted especially medical, chemical and pharmaceutical experience. What kind of methodological attitudes, values of life did evoke this long period of resistance, and its future end?

Third, what, in terms of information chemistry, determines the chemical properties: the structure of the electron shells, the structure (composition) of the atomic nucleus or "atomic weight"? Through what kind of configuration 
these three determining factors are interlinked? Is it right to speak about the chemical properties of objects in relation to the subatomic order? It, of course, should be offered a new understanding of the chemical element (or we should openly get rid of this concept). What is the specifics of the chemical law, first of all, of the periodic law? What exactly caused its necessity? Was in the early stages of evolution of the universe, when the chemical structures have not arisen yet, some kind of predetermined occurrence of chemicals laws in the future? If so, how the relevant the "potential" and "creativity" were present on the substrate of the sub-chemical level of complexity?

Fourth, revealing the essence of the information, you must override the correlative concept of entropy. Entropy is treated firstly as a measure of irreversible dissipation of energy; secondly, as a measure of the probability of the macroscopic state; Thirdly, as a measure of the uncertainty that is a measure of incomplete information messages. Only in this case it can be argued that the amount of information corresponding to the degree of organization of the system (otherwise, it will match what is not clear). Thus, when the substance goes from the gaseous state into the solid state entropy of the system becomes reduced and at the same time the amount of information about the location of molecules increases. In the structure of a living organism embodied much more information than in the structure of the metal lattice. However, when Shannon defined the information as the information that existed before relieving their production uncertainty, he deliberately abstracted from such "human" qualities of knowledge, as meaning, value, purpose! Today, this fundamental assumption has a boomerang on the positions of supporters of both main concepts of information. They are trying not to notice this fact. And in vain. Supporters of the first concept consider information to be a universal property of all nature-related systems with the ability to perceive, store and convert environmental impacts. The sources, carriers, consumers of information act, any material objects. The trouble is that, if the category does not capture information specifically human being-existence, understanding and experience of forming part of one world, it can not be considered as universal. Supporters of the other concepts are more cautious and believe that the information possessed only by living and self-governing system or, moreover, using the category of "information" only in relation to consciousness, in relation to the systems established and operating with the participation of the people. But in this case, we fail to avoid inconsistencies. It turns out that the category of Information describes only the physical aspect of human behavior, whose essence eludes conceptualization means of information theory. The appeal to the versions dating back to the theory of W. Ashby do not save the situation as well: the more different elements a set includes, the more information it contains. Information reflects diversity, overcoming of identity, function of the number of elements of their combinatorial relations (combinatorial approach) or function of differences of spatial structures (topological approach). The researcher glides past the existing mental, biological and even chemical phenomena that dominate the physical reality. Mind, life and chemistry are captured intuitively. Their presence is, strictly speaking, does not arise from physical observations (remember the sad experience of Descartes, and for failing to prove that the animals and the people are not perfect machine guns, and perhaps no less sad experience of those who believe only the chemistry section of physics). Thus, the development continualism inevitably requires a revision of the content of the concepts of entropy and information, including relationships between them. 
Fifth, what content should be, in terms of information chemistry, put in the concept of "chemical evolution"? As for chemistry, the theory of evolution is a long time in the shadow of the mature systems principle. So, even Boyle, formulated the concept of a chemical element, at the same time expressed doubts about its immutability. In general, the problem of evolution is divided into three main questions. How and why something new appears (new forms, elements, properties, processes)? And how this new is saved? Why is a particular focus of development (in the history of the individual chemical structures in the history of chemical reality in general)? Depending on the answers to these questions, we may add up different evolutionary theories.

Summarizing the short discussion, we can say that the information chemistry (and continualism in general) is at the beginning of its career. This promising scientific and philosophical concept faces a two-sided task: to explain the nature of the chemistry (define the subject of chemistry) and, at the same time to carry out a reflection on their own grounds, clearly understand their place in the history of ideas in natural science.

\section{References}

1. Jantsch E. The Self-Organizing Universe: Scientific and Human Implications of the Emerging Paradigm of Evolution, New York: Pergamon Press, 1980. 343 p.

2. Global'nyi evoliutsionizm (filosofskii analiz) [Global evolutionism (philosophical analysis)] / Ed. by L.V. Fesenkov. Moscow, Institute of Philosophy, Russian Academy of Sciences, 1994. 149p.

3. Mineev V.V. Vvedenie $v$ istoriiu i filosofiu nauki [Introduction to the history and philosophy of science]. Ed. 2nd, rev. and add. Krasnoyarsk: Krasnoyarsk state pedagogical university named after V.P. Astafiev, 2009. 456 p.

4. Svitin A.P. Ne-Razrushaiushchee Poznanie: Summa Ontologii [Non-Destructive Knowledge: The Sum of Ontologies]. Krasnoyarsk: Siberian Federal University, 2011. 270 p.

5. Heidegger M. Vremia i bytie: Stat'i i vystupleniia [Time and Being: Articles and Speeches]. M .: Republic, 1993. 447 p.

6. Plato. Timei [Timaeus] // V.3. Part 1. Moscow, Misl, 1971, pp. 455-541.

7. Newton I. Optika, ili traktat ob otrazheniiakh, prelomleniiakh, izgibaniiakh i tsvetakh sveta [Optics, or a treatise on the reflection, refraction, bending of light and colors]. 2nd ed. Moscow, Gostekhizdat, 1954. 367 p. 


\title{
Континуалистика Александра Свитина \\ и западная научно-философская традиция: \\ к вопросу об основаниях информационной химии
}

В.В. Минеев

Красноярский государственный педагогический университет им. В.П. Астафьева

Россия, 660049, Красноярск, ул. Лебедевой, 89

\begin{abstract}
Данная статья посвящена анализу монографии профессора А.П. Свитина «НЕ-разрушающее познание: Сумма онтологий». Критически рассматриваются сильные и слабые стороны оригинальной научно-философской концепции, предложенной А.П. Свитиным. В частности, предпринимается попьтка оценить возможности континуалистики для дальнейшей эволюиии химической науки. Показано, что информационная химия является скорее диалектическим отриианием информационной физики, чем ее прямым продолжением.
\end{abstract}

Ключевые слова: информационная химия, континуалистика, проблема бытия, история науки, философия науки.

Научная специальность: 09.00.00 - философские науки. 